\title{
POTENCIAL DE EMISSÃO DE METANO EM LAVOURAS DE ARROZ IRRIGADO
}

\author{
METHANE EMISSION POTENTIAL IN FLOODED RICE FIELDS
}

\author{
Dirceu Agostinetto ${ }^{1}$ Nilson Gilberto Fleck ${ }^{2}$ \\ Mauro Antonio Rizzardi ${ }^{3}$ Alvadi Antonio Balbinot $\mathbf{J r}^{4}$
}

- REVISÃO BIBLIOGRÁFICA -

RESUMO

Nos últimos anos, grande atenção tem sido dirigida aos problemas potenciais ocasionáveis pelo "efeito estufa". $O$ homem, através da atividade industrial, consumo de combustíveis fósseis, destruição de florestas e da adoção de certas práticas agrícolas, é o principal responsável pelo fenômeno. Os principais gases que causam o efeito estufa são dióxido de carbono $\left(\mathrm{CO}_{2}\right)$, metano $\left(\mathrm{CH}_{4}\right)$, óxido nitroso $\left(\mathrm{N}_{2} \mathrm{O}\right)$ e clorofluorcarbonos $(\mathrm{CFCs})$. $O$ metano destaca-se dentre eles pela quantidade produzida $e$ pela atividade na absorção do calor atmosférico. As principais fontes produtoras de metano são solos naturalmente alagados ou cultivados sob inundação, os quais respondem por aproximadamente $40 \%$ do total de metano emitido; destes, $37 \%$ são emitidos a partir do arroz cultivado sob inundação. Neste contexto, a presente revisão de literatura tem como objetivos descrever os processos que governam a produç̃o e a emissão de metano, bem como discutir práticas de manejo e características da cultura que afetam a emissão do gás. Do total de metano originado em lavouras de arroz durante a estação de crescimento, entre 60 e $90 \%$ dá-se através das plantas de arroz. Embora o metano não seja o principal responsável pelo efeito estufa e a orizicultura não represente a maior fonte produtora de metano, a redução na emissão do gás poderá ser alcançada através de alterações nas práticas de cultivo do arroz. Dentre as alternativas que podem ser trabalhadas incluem-se os manejos da água de irrigação e da adubação e a utilização de cultivares do cereal que apresentem menor número de aerênquimas e menor produção de fitomassa, mas que mantenham o potencial de rendimento da cultura.

Palavras-chave: Oryza sativa, efeito estufa, cultivares de arroz. características de planta.

\section{SUMMARY}

In the last years, great attention has been directed to potential problems caused by the "greenhouse effect". Man, through industrial activities, fossil fuel consumption, forest destruction, and adoption of some agronomic practices, has been the main responsible for such phenomenon. The main gases that cause the greenhouse effect are carbon dioxide $\left(\mathrm{CO}_{2}\right)$, methane $\left(\mathrm{CH}_{4}\right)$, nitrous oxide $\left(\mathrm{N}_{2} \mathrm{O}\right)$, and chlorofluorocarbons (CFCs). Methane stands out amongst them by the amount produced and by its activity in the absorbing atmospheric heat. The main methane producing sources are soils naturally flooded or cultivated under flooding conditions, which represent approximately $40 \%$ of the total methane emitted; from this amount, $37 \%$ is emitted by rice cultivated under flooding conditions. In this context, the present review has as main purposes to describe processes responsible for methane production and emission, as well as to discuss management practices and rice plant characteristics which affect emission of this gas. From the total methane originated in rice fields during its growth cycle, between 60 to $90 \%$ comes from rice plants. Although methane is not the main gas responsible for the greenhouse effect and rice crop does not represent the main methane source, the reduction in the emission could be accomplished through changes in rice cultural practices. Amongst alternatives that can be worked out are management of irrigation water and fertilizer applied, and cropping of rice cultivars that present lower number of aerenchyma and lower biomass production, whereas maintaining rice grain yields potential.

Key words: Oryza sativa, greenhouse effect, rice cultivars, plant characteristics.

\footnotetext{
${ }^{1}$ Engenheiro Agrônomo, Mestre em Fitotecnia, Aluno do Programa de Pós-graduação em Fitotecnia da Faculdade de Agronomia da Universidade Federal do Rio Grande do Sul (UFRGS). CP 776, 91501-970, Porto Alegre, RS. E-mail:dirceua@ vortex.ufrgs.br.

${ }^{2}$ Engenheiro Agrônomo, PhD., Professor do Departamento de Plantas de Lavoura da Faculdade de Agronomia da UFRGS, Av. Bento Gonçalves, 9090, CP 776, 91501-970, Porto Alegre, RS. Bolsista do CNPq. Autor para correspondência.

${ }^{3}$ Engenheiro Agrônomo, Mestre em Fitotecnia, Professor do Departamento de Fitotecnia da Universidade de Passo Fundo. Aluno do Programa de Pós-graduação em Fitotecnia da Faculdade de Agronomia da UFRGS.

${ }^{4}$ Engenheiro Agrônomo, Aluno do Programa de Pós-graduação em Fitotecnia da Faculdade de Agronomia da UFRGS.
} 


\section{INTRODUÇÃO}

$\mathrm{O}$ aumento da temperatura global (efeito estufa) poderá promover várias anomalias climáticas. Do ponto de vista biológico, o aumento da temperatura poderá encurtar o ciclo das culturas e representar antecipações nas épocas de semeadura e de colheita, havendo também maiores riscos de salinização do solo e de incidências de pragas e de ervas daninhas. Em países de clima tropical, como é o caso do Brasil, poderá haver redução de até $10 \%$ no potencial produtivo por conta da maior evaporação da água e do conseqüente estresse hídrico às plantas (AMADO \& REINERT, 1999).

Os principais gases responsáveis pelo efeito estufa são: dióxido de carbono $\left(\mathrm{CO}_{2}\right)$, produzido através da queima de combustíveis fósseis, queima da biomassa e do revolvimento do solo; metano $\left(\mathrm{CH}_{4}\right)$, produzido principalmente em solos naturalmente inundados e em lavouras de arroz; clorofluorcarbonos (CFCs), oriundos da atividade industrial; e, óxido nitroso $\left(\mathrm{NO}_{2}\right)$, liberado após aplicação de fertilizantes nitrogenados em áreas agrícolas (RUSCHEL, 1992; MILICH, 1999). Dentre esses gases, o de maior destaque é o metano, devido à quantidade emitida e à atividade desempenhada na absorção radioativa. Com relação à quantidade produzida, o metano é o segundo gás mais importante, sendo superado apenas pelo $\mathrm{CO}_{2}$. Já, em relação à atividade, se por um lado o metano apresenta-se como causador do efeito estufa, com capacidade de absorção de calor atmosférico 15 a 40 vezes superior à do $\mathrm{CO}_{2}$ (RUSCHEL, 1992; CAO et al., 1998), por outro lado, sua reação com $\mathrm{O}_{2}$, na presença de óxido nítrico, forma ozônio na troposfera terrestre (MILICH, 1999). Além disso, o metano também minimiza o ataque de átomos de cloro ao ozônio, reagindo com o cloro e formando ácido clorídrico, o qual atua como reservatório inerte de cloro (MILICH, 1999). Ainda, segundo o autor, a reação-chave do metano na atmosfera inclui sua oxidação com radicais hidroxilas, formando água.

A concentração troposférica de metano é estimada em 4700 teragramas $\left(\mathrm{Tg}=10^{12} \mathrm{~g}\right.$ ) (SASS, 1999) e a emissão anual oriunda de solos naturalmente inundados e de lavouras de arroz é estimada em $145 \mathrm{Tg}$ ano $^{-1}$, a qual tem aumentado a uma taxa de $1 \%$ ao ano (CAO et al., 1998). As principais fontes que originam metano são: solos naturalmente inundados, lavouras de arroz, fermentação entérica, gás natural, queima da biomassa, atividade de cupins, aterros de lixo, minas de carvão e oceanos (CICERONE \& OREMLAND, 1988; MILICH, 1999). Solos naturalmente inundados ou cultivados sob inundação respondem por aproximadamente $40 \%$ do total de metano emitido na atmosfera (CICERONE \& OREMLAND, 1988; IPCC, 1995; CAO et al., 1998; MILICH , 1999).

$\mathrm{O}$ arroz cultivado sob inundação contribui com cerca de 15 a $20 \%$ do total de metano emitido para a atmosfera; este valor é estimado em 33 a 53 Tg ano $^{-1}$ (SASS, 1994; IPCC, 1995; CAO et al., 1998). Dentre os países que mais emitem metano, o Brasil ocupa o décimo primeiro lugar, com uma emissão estimada em $0,53 \mathrm{Tg} \mathrm{ano}^{-1}$ (SASS, 1999). A taxa de emissão de metano a partir de lavouras de arroz depende do estádio de desenvolvimento das plantas, bem como de condições que afetam o solo, como regime de irrigação, adição e tipo de fertilizantes, deposição de resíduos orgânicos e condições climáticas (NEUE, 1993).

Embora a lavoura de arroz cultivado sob inundação represente, globalmente, menos de $20 \%$ do total de metano emitido, seu papel de destaque, dentre as fontes produtoras, deve-se ao fato da cultura do arroz ser uma das poucas fontes de metano onde é possível modificar o padrão de emissão. Projeções baseadas na taxa de crescimento da população mundial indicam que haverá aumento de $65 \%$ na demanda de arroz até o ano 2020 (SASS, 1999). O aumento na produção de grãos do cereal poderá ser obtido pelo aumento da área cultivada, adoção de cultivares mais produtivas e intensificação das práticas culturais, o que poderá acarretar aumento na emissão de metano. Neste contexto, a presente revisão de literatura tem como objetivos descrever os processos que governam a produção e a emissão de metano, bem como discutir práticas de manejo e características da cultura que afetam a emissão do gás.

\section{PRODUÇÃO DE METANO}

O metano produzido em lavouras de arroz sob inundação é o produto final da decomposição anaeróbica de compostos orgânicos. As maiores fontes destes no solo são a matéria orgânica natural, exudatos das raízes das plantas e a matéria orgânica incorporada como fitomassa das plantas infestantes e restos culturais (NEUE, 1993). Solos cultivados sob inundação apresentam condições favoráveis à metanogênese, devido ao elevado conteúdo de carbono e à baixa taxa de decomposição da fitomassa em condições anaeróbicas. Esse processo é realizado por bactérias metanogênicas que possuem habilidade em usar compostos carbônicos de baixo peso molecular para a produção de energia (REDDY \& PATRICK, 1984). Desta forma, essas bactérias são dependentes de consórcio com outras 
bactérias hidrolíticas e fermentativas que reduzem o peso molecular dos compostos vegetais (ZENGLER et al., 1999). Características do ambiente, como radiação, temperatura e precipitação pluvial, e do solo, como conteúdo de matéria orgânica, teor de água, potencial de redução e $\mathrm{pH}$, as quais alteram a constituição e a taxa de liberação de exudatos, bem como da matéria orgânica, afetam a produção de metano (Figura 1).

Nem todo o metano produzido na camada reduzida do solo atinge a atmosfera; parte é transferida para o subsolo e parte é oxidada pelas bactérias metanotróficas aeróbicas presentes junto à camada oxidada do solo submerso e na rizosfera das plantas de arroz, onde existe oxigênio obtido pelo transporte de ar ao solo através da planta de arroz (RUSCHEL, 1992). O metano é absorvido pelas raízes das plantas de arroz junto com a água ou em estado gasoso, sem a necessidade de absorção de água, sendo emitido para a atmosfera principalmente por difusão através dos aerênquimas das plantas de arroz e também pela ebulição de bolhas de gás (WASSMANN et al., 1996). A seguir são apresentados os principais fatores que afetam a produção e emissão de metano para a atmosfera a partir de lavouras de arroz.

\section{a) Matéria orgânica}

A metanogênese em solos alagados é influenciada pela disponibilidade de substratos fermentativos, sendo a taxa de produção de metano aumentada com a adição de restos culturais ou pela adubação verde. Por exemplo, a adição de 6 e $9 \mathrm{t} \mathrm{ha}^{-1}$ de palha aumentou a taxa de emissão de metano em 1,8 e 3,5 vezes, comparativamente à adubação mineral, embora a aplicação de $12 \mathrm{t} \mathrm{ha}^{-1}$ reduzisse a emissão de metano (YAGI \& MINAMI, 1990). De acordo com os autores, a redução da produção de metano quando da aplicação de elevada quantidade de matéria orgânica, deve-se à inibição da metanogênese por produtos fermentativos oriundos da decomposição da matéria orgânica. Por outro lado, KLUDZE \& DELAUNE (1995) atribuíram a redução verificada na taxa de emissão de metano, quando a adição de palha aumentou de 11 para $22 \mathrm{t}$ ha $^{-1}$, à redução na difusão do gás, visto que no tratamento sem cultivo a emissão de metano aumentou com o incremento da quantidade de palha aplicada.

Em trabalho desenvolvido por BHARATI et al. (2001), os autores observaram que, em solo inundado, a quantidade de carbono mineralizável aumentou, comparativamente ao solo não inundado,

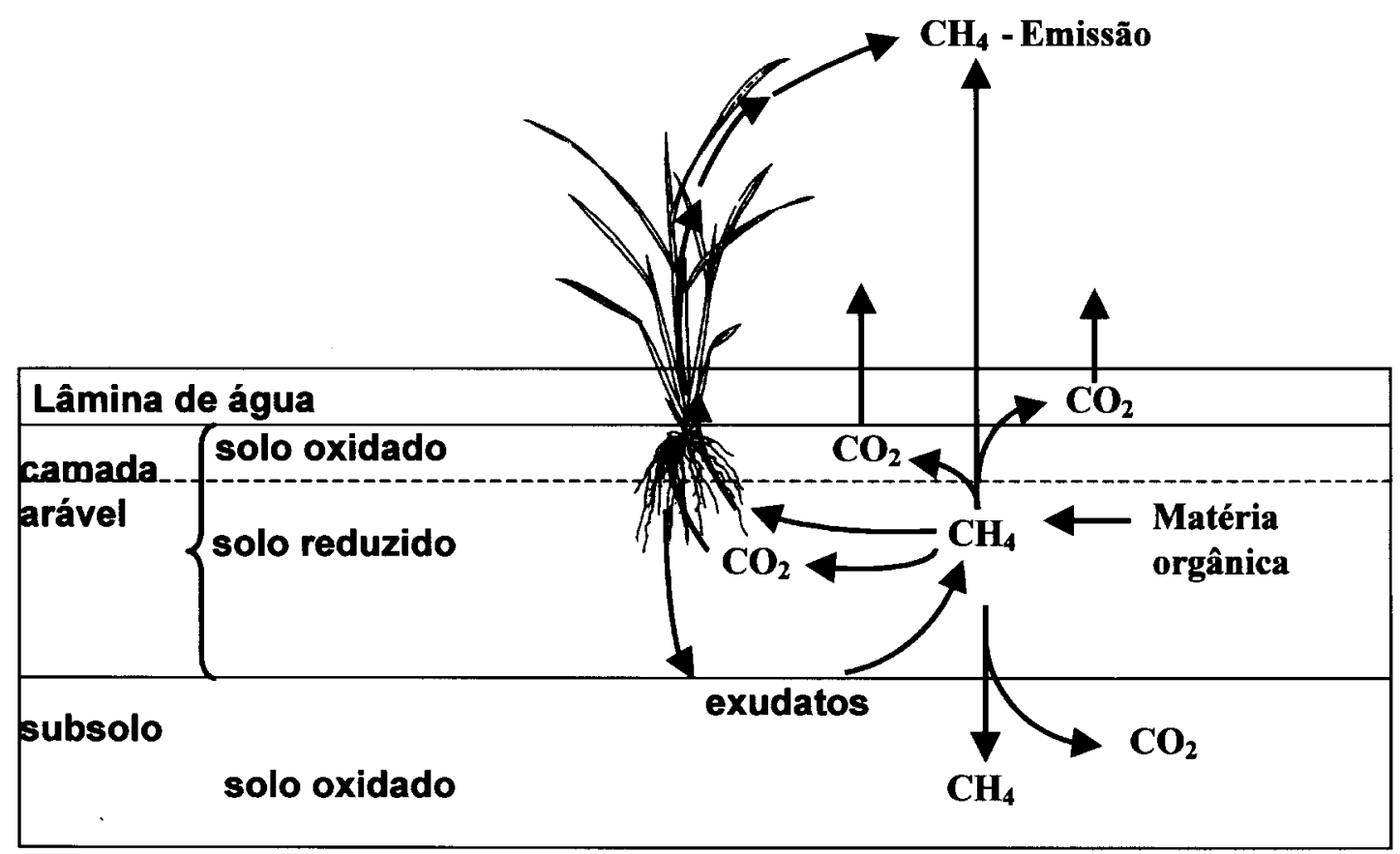

Figura 1 - Fluxograma representativo da produção e emissão de metano em lavouras de arroz. Adaptado de KIMURA \& MINAMI (1995) 
e que em condição de inundação contínua, os níveis de carbono mineralizável diminuíram durante o estádio reprodutivo da cultura, com concomitante aumento da emissão de metano. Isso sugere, segundo os autores, que o carbono mineralizável disponível foi utilizado para a produção do gás. Os autores observaram correlação positiva significativa $\left(r^{2}=0,97\right)$ entre a média de metano emitido e o conteúdo de carbono mineralizável no solo.

A adição de palha de arroz, em relação à aplicação de adubação química, aumentou, em média, 1,5 (NUGROHO et al., 1996) a 1,8 vezes (SUBADIYASA $\boldsymbol{e t} \boldsymbol{a l} ., 1997$ ) a emissão de metano. $A$ adição de adubação verde também aumentou a taxa de emissão de metano em 1,6 e 4,2 vezes, em comparação à adubação química, respectivamente para o primeiro e segundo anos de estudo conduzido por YANG \& CHANG (2001). Já, BOSSIO et al. (1999) observaram que a matéria orgânica disponível no solo aumentou em 1,5 vezes, ao compararem os sistemas onde a palha de arroz foi incorporada e queimada, e que a emissão de metano reduziu 4,5 vezes quando a palha foi queimada. Porém, cabe ressaltar que a queima da palha não é uma prática recomendável, pois além de reduzir a incorporação de matéria orgânica ao solo, emitirá $\mathrm{CO}_{2}$ para a atmosfera.

Embora adição de palha ou adubação verde incrementem a taxa de emissão de metano, a adição de resíduo vegetal não pode ser eliminada do sistema, pois solos intensamente cultivados e com reduzida adição de matéria orgânica tornam-se empobrecidos e o rendimento das culturas diminui.

\section{b) Teor de água no solo}

O regime hídrico é um importante fator que influencia a liberação de gases entre o solo e a atmosfera, tendo efeito direto nos processos envolvidos na produção, oxidação e transporte de metano. Solos alagados apresentam decréscimo de 10000 vezes na difusão de gases, o que resulta em mudanças físico-químicas e biológicas no solo, propiciando condições que favorecem a produção e a emissão de metano (BHARATI et al., 2001). A produção de metano depende do conteúdo de água no solo, sendo variável com a inundação ou a drenagem do solo. Quando o conteúdo de água no solo é inferior a $23 \%$, a produção de metano é baixa, podendo ser desconsiderada; no entanto, foi verificada correlação linear entre produção total de metano e conteúdo de água no solo para valores entre 17 e $67 \%$ (YANG \& CHANG, 1998). Ainda, segundo os autores, quanto maior for a submersão do solo, maiores serão a taxa de produção de metano e o total produzido, o que se deve ao incremento da anaerobiose. Por outro lado, MOORE \& DALVA (1993) observaram que a produção de metano aumentou com o aumento da submersão do solo até $10 \mathrm{~cm}$, devido ao estímulo da anaerobiose, diminuindo com maiores alturas da lâmina de água devido ao aumento da oxidação do metano. Esses mesmos autores verificaram que a taxa de emissão de metano apresentou relação logarítmica negativa com o aumento da lâmina de água de 0 para $60 \mathrm{~cm}$.

Grande parte do metano produzido permanece retido no solo e pode ser oxidado pela aeração do solo promovida por drenagens durante o ciclo de desenvolvimento da cultura ou próximo à colheita, embora a maior parte do metano retido escape para a atmosfera imediatamente após a água ser retirada e os macroporos do solo serem aerados (DEEPANJAN et al., 1998). O metano retido no solo também pode ser liberado para a atmosfera como resultado de práticas culturais adotadas em diferentes sistemas de cultivo, tais como: formação da lama e destorroamento (nos sistemas prégerminado e transplante de mudas), transplante de plantas (no sistema transplante de mudas), aplicação de agrotóxicos e de fertilizantes, e colheita (em todos os sistemas). Estas práticas podem representar de 10 a $20 \%$ do total de metano emitido durante a estação de crescimento (MITRA et al., 1999).

\section{c) Características do solo}

Solos recomendados para o cultivo do arroz caracterizam-se por apresentar pequena quantidade de $\mathrm{O}_{2}$, alto teor de umidade e alta quantidade relativa de matéria orgânica, propiciando um ambiente ideal para proliferação de bactérias metanogênicas. Várias são as características do solo que contribuem para a produção de metano. Dentre elas, destacam-se:

\section{- Potencial de redução}

A submersão de um solo aeróbico resulta em sucessivas reações de redução. Inicialmente, as mudanças químicas predominantes, devido à inundação do solo, são o desaparecimento do $\mathrm{O}_{2}$, a decomposição anaeróbica da matéria orgânica, redução do $\mathrm{NO}_{3}^{-}$para $\mathrm{N}_{2} \mathrm{O}$ e $\mathrm{N}_{2}, \mathrm{Fe}^{3+}$ para $\mathrm{Fe}^{2+}$, $\mathrm{Mn}^{4+}$ para $\mathrm{Mn}^{2+}, \mathrm{SO}_{4}^{2-}$ para $\mathrm{SO}^{2-}$ e acumulação de $\mathrm{CO}_{2}$ ou sua redução a $\mathrm{CH}_{4}$ (WANG et al., 1993). O potencial de redução do solo varia de 400 a $600 \mathrm{mV}$ em solos aerados e de 100 a $-300 \mathrm{mV}$ em solos reduzidos ou anaeróbicos (KLUDZE et al., 1993).

As bactérias metanogênicas apresentam máxima população em solos completamente reduzidos. KLUDZE $\boldsymbol{e t}$ al. (1993) observaram que a metanogênese era estimulada apenas quando o 
potencial de redução era inferior a $-200 \mathrm{mV}$. Os autores verificaram que a produção de metano aumentou 10 vezes e que a emissão aumentou 17 vezes quando o potencial de redução do solo foi reduzido de -200 para $-300 \mathrm{mV}$. Ainda, segundo os autores, a interferência do potencial de redução do solo influencia o fluxo de metano em lavouras de arroz de duas formas: pela determinação direta do aumento na taxa de produção de metano no solo e por provocar mudanças morfofisiológicas nas plantas de arroz, induzindo a formação de aerênquimas, o que facilita a liberação do metano do solo para atmosfera. Da mesma forma, WANG et al. (1993) observaram que o potencial crítico de redução do solo para iniciar a produção de metano encontra-se entre -150 e $-160 \mathrm{mV}$.

Em pesquisa que avaliou o efeito de cultivares de arroz na emissão de metano, foi observado que os baixos valores do potencial de redução do solo, variáveis de $-112 \mathrm{a}-283 \mathrm{mV}$, foram negativamente correlacionados com a emissão de metano para todas as cultivares (MITRA et al. 1999). Já GAUNT et al. (1997), utilizando modelo de regressão múltipla, concluíram que a produção de metano está na dependência da disponibilidade de substrato e do potencial de redução do solo.

\section{$-\mathbf{p H}$}

O pH dos solos alcalinos ou ácidos tende a se tornar neutro após a submersão. A maioria dos organismos metanogênicos é neutrófica e apresenta eficiente produção de metano quando o $\mathrm{pH}$ varia de 6,4 a 7,8; sendo que a produção diminui em $\mathrm{pH}$ menor ou maior (WANG et al., 1993). Os autores encontraram alta produção de metano em pH de 6,9 a 7,1. Já MITRA et al. (1999) observaram que, durante a estação de crescimento, o pH variou de 7,6 a 8,0 e que não houve correlação entre o pH do solo e a taxa de emissão de metano.

Em trabalho conduzido para determinar a produção diária de metano, foi constatado que cada grama de solo incubado produziu 33 e $65 \mu \mathrm{g}$ de metano para valores de $\mathrm{pH} 4,3$ e 8,7, respectivamente (YANG \& CHANG, 1998). Os autores verificaram que a maior produção de metano ocorreu para valores de $\mathrm{pH}$ entre 6,0 e 7,7 e que, nessa faixa, não ocorreram diferenças na taxa de produção; porém, a produção de metano foi inibida quando o $\mathrm{pH}$ do solo foi inferior a 3,2 ou superior a 9,3. Por outro lado, WANG et al. (1993) constataram que a inibição da produção de metano em solo incubado ocorreu para valores de $\mathrm{pH}$ inferiores a 5,8 ou superiores a 8,8. A diferença observada entre os resultados relatados pode deverse ao tipo de solo utilizado ou à diferença do potencial de redução do solo durante a condução dos experimentos. De acordo com o exposto, constata-se que pequenas reduções no valor do $\mathrm{pH}$ do solo podem ocasionar drásticas reduções na emissão de metano, o que sugere que a adoção de práticas agrícolas que promovam reduções no $\mathrm{pH}$ podem diminuir efetivamente a produção de metano.

\section{- Temperatura}

A produção de metano depende da temperatura do solo. Por um lado, redução na altura da lâmina de água pode aumentar a temperatura do solo e, conseqüentemente, a produção de metano, por outro lado, maior altura da lâmina de água pode aumentar a produção de metano, por incrementar a anaerobiose. A taxa máxima de produção de metano foi obtida à temperatura de $37^{\circ} \mathrm{C}$; temperaturas superiores diminuem a taxa e atrasam o tempo para obtenção dos maiores níveis de produção de metano (YANG \& CHANG, 1998). Os autores observaram existir correlação positiva entre o metano total produzido e a temperatura de incubação do solo para valores entre 15 e $37^{\circ} \mathrm{C}$, faixa em que ocorreu acréscimo de $0,22 \mu \mathrm{g} \mathrm{g}^{-1}$ na produção de metano para cada aumento de $1^{\circ} \mathrm{C}$. Por outro lado, houve correlação negativa para temperaturas entre $37 \mathrm{e}$ $50^{\circ} \mathrm{C}$, com decréscimo de $0,21 \mu \mathrm{g} \mathrm{g}^{-1}$ na produção de metano para cada aumento de $1^{\circ} \mathrm{C}$. Segundo foi relatado por MOORE \& DALVA (1993), a emissão de metano foi 6,6 vezes maior à temperatura de $23^{\circ} \mathrm{C}$ do que a $10^{\circ} \mathrm{C}$.

\section{FORMAS DE EMISSÃO DE METANO}

A necessidade de transportar oxigênio $\left(\mathrm{O}_{2}\right)$ atmosférico para a manutenção da respiração aeróbica em raízes desenvolvendo-se em condição de anoxia força as plantas de arroz a desenvolverem aerênquimas (espaços intercelulares), tanto nas raízes como na parte aérea (ARMSTRONG, 1979). Embora a função primária dos aerênquimas em plantas de arroz seja transportar $\mathrm{O}_{2}$ para as raízes submersas, neste processo outros gases, como $\mathrm{CO}_{2}$, $\mathrm{N}_{2}, \quad \mathrm{~N}_{2} \mathrm{O}$ e $\mathrm{CH}_{4}$, também são transportados (WASSMANN et al., 1996; WANG et al., 1997). O efeito da presença de plantas de arroz é fundamental para o processo de emissão de metano, visto que 60 a $90 \%$ do gás que chega à atmosfera passa pelas plantas de arroz e, na ausência de vegetação, a quantidade emitida é insignificante (WASSMANN et al., 1996).

Em estudo realizado por BUTTERBACHBAHL et al. (1997), os autores demonstraram que o corte e a remoção da zona de transição da raiz para o caule resultaram em significativo aumento do 
transporte de gás, indicando que este é o passo decisivo da passagem do metano pela planta de arroz. Por outro lado, AULAKH et al. (2000b), ao examinarem aparência, distribuição e densidade de aerênquimas de diferentes partes de plantas de três cultivares de arroz com ciclos diferentes, nos estádios de iniciação da panícula, florescimento e maturação da cultura, concluíram, com base em todas as cultivares analisadas, que existe uma continuidade dos canais de aerênquimas das raízes para o colmo e deste para as folhas, funcionando como condutores para o transporte bidirecional de gases.

As plantas de arroz apresentam grande variação nas características morfofisiológicas, inclusive diferenças na capacidade de transporte de metano (CTM). Em pesquisa realizada por AULAKH et al. (2000a), os autores observaram diferenças marcantes na CTM entre 12 cultivares de arroz, as quais apresentaram três diferentes padrões de CTM. Mais recentemente, AULAKH et al. (2000b) observaram que o aumento da densidade de pequenas $\left(>1 \times 10^{3}\right.$ a $\left.5 \times 10^{3} \mu \mathrm{m}^{2}\right)$ e médias $\left(5 \times 10^{3}\right.$ a $20 \times 10^{3} \mu \mathrm{m}^{2}$ ) lacunas de aerênquimas nas regiões internodais da base do colmo não apresenta relação com a CTM em cultivares de arroz. Por outro lado, grandes lacunas de aerênquimas $\left(>20 \times 10^{3} \mu \mathrm{m}^{2}\right)$ exibem correlações altamente significativas com a CTM de diferentes cultivares. Isso sugere que a grande variação na CTM em plantas de arroz, durante os diferentes estádios de desenvolvimento, relaciona-se com as características estruturais.

A formação de aerênquimas em plantas de arroz é afetada pelo potencial de redução da rizosfera e, em condição de elevada redução do solo, ocorre o desenvolvimento de aerênquimas grandes (KLUDZE et al., 1993). Práticas de manejo, como alterações na densidade de semeadura, espaçamento entre linhas e suprimento de nutrientes, determinam o número de raízes e afilhos da planta de arroz e, conseqüentemente, a formação de aerênquimas.

\section{ESTRATÉGIAS PARA MINIMIZAR A PRODUÇÃO DE METANO}

Estimativas apontam que reduções de 10 a $15 \%$ no total de metano emitido poderão estabilizar sua concentração na atmosfera (IPCC, 1995). Esta redução na emissão deverá ser conseguida através da alteração das práticas de cultivo do arroz, especialmente no manejo da água de irrigação, da adição e tipo de adubação e da utilização de cultivares que emitam menor quantidade de metano. As principais estratégias que apresentam potencial para diminuir a emissão de metano são descritas a seguir.

\section{a) Manejo da água}

O manejo da água é de fundamental importância para o sucesso da produção de arroz irrigado por inundação e na redução da produção e emissão de metano. Considerando-se o suprimento de água para a cultura do arroz, basta que o solo se mantenha uniformemente saturado durante todo o ciclo; porém, há três fases durante o ciclo de desenvolvimento em que a cultura é mais exigente: estabelecimento do cultivo, afilhamento e no período entre o início da diferenciação da panícula e o enchimento de grãos (EMBRAPA, 1999).

A taxa de emissão de metano é altamente sensível ao manejo da água. Drenagens periódicas resultam em decréscimos na emissão de metano e podem representar o método mais eficiente para minimizar a emissão do gás (SASS et al., 1992; YAGI et al., 1996; SASS, 1999). Assim, SASS et al. (1992) verificaram que uma única drenagem durante a estação de crescimento do arroz reduziu a taxa de emissão de metano em 50\%. Adicionalmente, múltiplas drenagens ( 2 a 3 dias), aproximadamente a cada 3 semanas durante toda a estação de crescimento, reduziram a emissão de metano para valores insignificantes. Da mesma forma, YAGI $\boldsymbol{e t}$ al. (1996) observaram que a inundação contínua emitiu aproximadamente duas vezes mais metano, em comparação com a irrigação intermitente, a qual era realizada por curtos períodos de tempo e algumas vezes durante a estação de crescimento.

Para as condições da região sul do Brasil, drenagens em período entre o final do estádio de afilhamento e o início da diferenciação da panícula e após o completo enchimento de grãos (maturação fisiológica), podem contribuir para redução na emissão de metano. Porém, a recomendação de drenagem no período inicial deve ser vista com ressalvas, pois a presença de lâmina de água sobre o solo é importante fator que contribui para o controle de plantas daninhas, para eficiência da adubação nitrogenada e para reduzir os efeitos negativos do frio no estádio reprodutivo.

\section{b) Adubação}

Conforme apresentado anteriormente, a adição de matéria orgânica ou adubação verde aumenta a emissão de metano, comparativamente à adubação mineral. Neste contexto, BRONSON et al. (1997) constataram que a adubação nitrogenada com uréia, comparativamente ao sulfato de amônio, aumentou em 2,7 e 4 vezes a emissão de metano quando a inundação foi mantida durante todo o ciclo 
da cultura ou quando o solo foi drenado no estádio de início da diferenciação da panícula, respectivamente.

Aplicações de sulfato de amônio e de uréia nas doses de 100 e $300 \mathrm{~kg} \mathrm{ha}^{-1}$ resultaram em reduções de 42 e $60 \%$ e 7 e $14 \%$, respectivamente, comparativamente a não aplicação (CAI et al., 1997). Também YANG \& CHANG (1998) verificaram que a produção de metano é reduzida e atrasada com aplicação de adubação nitrogenada. Esses autores constataram que a produção de metano diminuiu significativamente com aplicação de $\mathrm{N}$ em doses superiores a $600 \mathrm{~kg}$ de $\mathrm{N} \mathrm{ha}^{-1}$. Por outro lado, SINGH et al. (1999) observaram que aplicação de uréia incrementou a emissão de metano, comparativamente a não aplicação. A variação observada entre as duas formas nitrogenadas pode ser explicada pelo fato do íon amônio competir com o metano para ser oxidado pelos organismos metanotróficos, aumentando a produção de metano; enquanto, o íon sulfato atua como um aceptor de prótons em condições anaeróbicas, reduzindo a produção de metano.

\section{c) Cultivares}

Diversos trabalhos encontrados na literatura relatam a existência de variabilidade entre cultivares para arroz na emissão de metano (SUBADIYASA et al., 1997; WANG et al., 1997; MITRA et al., 1999; SINGH et al., 1999). A classificação das cultivares pode ser realizada de acordo com o padrão de desenvolvimento. Para a maioria das cultivares, a maior taxa de emissão de metano é verificada no estádio reprodutivo (60 a 80 dias após a semeadura), estando relacionada com o aumento de exudatos da raiz que servem como substrato para as bactérias metanogênicas (RUSCHEL, 1992), e época em que também ocorre o completo desenvolvimento dos aerênquimas (AULAKH et al., 2000b).

As características morfológicas das plantas de arroz apresentam respostas variadas em relação à emissão de metano. SINGH et al. (1999) observaram correlações positivas entre a taxa de emissão de metano e o número de afilhos, o volume e a porosidade da raiz e o rendimento de grãos. Porém, as variáveis fitomassa da parte aérea e da raiz não apresentaram correlações positivas com a emissão de metano. Por outro lado, WANG et al. (1997) verificaram correlações significativas entre taxa de emissão de metano e massa seca da raiz $\left(r^{2}=0,85\right)$ e entre taxa de emissão de metano e número de afilhos $\left(\mathrm{r}^{2}=0,80\right)$. Já MITRA et al. (1999) observaram que, de modo geral, as cultivares que apresentam maiores emissões de metano são as que apresentam maior produção de fitomassa.

Conforme foi comprovado, existe variabilidade entre cultivares de arroz com relação às características morfológicas e o padrão de emissão de metano. Em sendo assim, uma meta do melhoramento genético deveria ser a de identificar características de planta mais relacionadas à produção e à emissão de metano e o desenvolvimento ou a seleção de cultivares que apresentem menor potencial de emissão desse gás.

\section{CONSIDERAÇÕES FINAIS}

Com base no que foi exposto, verifica-se que o gás metano não se constitui no principal responsável pelo efeito estufa e que a orizicultura não é a maior fonte produtora de metano. Além disso, foi possível verificar que a lavoura de arroz representa uma das poucas fontes produtoras de metano nas quais a taxa de emissão pode ser reduzida através de alterações das práticas de cultivo do arroz, especialmente manejos da água de irrigação e da adubação, e da seleção de cultivares do cereal que apresentem menor número de aerênquimas e menor produção de fitomassa.

De modo diferente do que ocorre em outras regiões produtoras de arroz no mundo, no Sul do Brasil é realizado somente uma safra por ano, nas áreas de cultivo de arroz. Embora esse fato possa parecer vantajoso do ponto de vista de produção de metano, acredita-se que essa possa equivaler-se às demais regiões do mundo, devido ao deficiente sistema de drenagem existente na maioria das áreas, que mantém o solo saturado durante grande parte do período de entresafra, e a utilização da resteva do arroz para alimentação de animais, especialmente bovinos, os quais, através da fermentação entérica, representam importante fonte produtora de metano. A mudanças desse panorama e a adoção de estratégias eficazes que visem reduzir a emissão de metano só serão possíveis a partir de estudos regionais, que quantifiquem a emissão de metano pela lavoura orizícola do Sul do Brasil, levando em conta sistemas de cultivo, características de solo e clima e de manejo da área no período após a colheita. Cabe ressaltar, por fim, que a modificação das práticas de cultivo não deve afetar negativamente o potencial produtivo da cultura.

\section{REFERÊNCIAS BIBLIOGRÁFICAS}

AMADO, T.J.C., REINERT, D.J. Qualidade ambiental e plantio direto na $10^{\text {a }}$ ISCO. Revista Plantio Direto, Passo Fundo, n.52, p.34-35, 1999.

ARMSTRONG, W. Aeration in higher plants. Advances in Botany Research, London, v.7, n.2, p.225-232, 1979. 
AULAKH, M., BONDENBENDER, J., WASSMANN, R., et $\boldsymbol{a l}$. Methane transport capacity of rice plants. II. Variations among different rice cultivars and relationship with morphological characteristics. Nutrient Cycling in Agroecosystems, Dordrecht, v.58, n.1-3, p.367-375, 2000a.

AULAKH, M.S., WASSMANN, R., RENNENBERG, H., et al. Pattern and amount of aerenchyma relate to variable methane transport capacity of different rice cultivars. Plant Biology, Stuttgart, v.2, n.2, p.182-194, 2000b.

BHARATI, K., MOHANTY, S.R., RAO, V.R., et al. Influence of flooded and non-flooded conditions on methane efflux from two soils planted to rice. Chemosphere - Global Change Science, Oxford, v.3, n.1, p.25-32, 2001.

BOSSIO, D.A., WILLIAM, R.H., MUTTERS, R.G., et al. Methane pool and flux dynamics in a rice field following straw incorporation. Soil Biology and Biochemistry, Oxford, v.31, n.9, p.1313-1322, 1999.

BRONSON, K.F., NEUE, H.U., SINGH, U., et al. Automated chamber measurements of methane and nitrous oxide flux in a flooded rice soil: I. Residue, nitrogen, and water management. Soil Science Society of America Journal, Madison, v.61, n.3, p.981-987, 1997.

BUTTERBACH-BAHL, K., PAPEN, H., RENNENBERG, H Impact of gas transport through rice cultivars on methane emission from rice paddy fields. Plant Cell Environment, Oxford, v.20, n.9, p.1175-1183, 1997.

CAI, Z., XING, G., YAN, X., et al. Methane and nitrous oxide emissions from paddy fields as affected by nitrogen fertilizers and water management. Plant and Soil, Dordrecht, v.196, n.1, p.7-14, 1997.

CAO, M., GREGSON, K., MARSHALL, S. Global methane emission from wetlands and its sensitivity to climate change. Atmospheric Environment, Oxford, v.32, n.19, p.32933299, 1998.

CICERONE, R.J., OREMLAND, R.S. Biogeochemical aspects of atmospheric methane. Global Biogeochemical Cycles, Washington, v.2, n.2, p.299-327, 1988.

DEEPANJAN, M., SUSHIL, K., JAIN, M.C. Methane entrapment in different rice soils of India. Current Science, Bangalore, v.75, n.3, p.576-583, 1998.

EMBRAPA CLIMA TEMPERADO. Arroz irrigado: recomendações técnicas da pesquisa para o Sul do Brasil. Pelotas : Embrapa Clima Temperado/IRGA/EPAGRI, 1999. 124p. (Embrapa Clima Temperado. Documento, 57).

GAUNT, J.L., BRAGAIS, N.J., GRANT, I.F., et al. Soil characteristics that regulate soil reduction and methane production in wetland rice soils. Soil Science Society of America Journal, Madison, v.61, n.5, p.1526-1531, 1997.

IPPC. Climate change 1994: radiative forcing of climate change. New York : Cambridge University, 1995. p.85-87.

KIMURA, M., MINAMI, K. Dynamics of methane in rice fields: emissions to the atmosphere in Japan and Thailand. In: PENG, S., INGRAM, K.T., NEUE, H.U., et al. (eds.) Climate change and rice. New Delhi : Thomson, 1995. p.30-45.
KLUDZE, H.K., DELAUNE, R.D., PATRICK JR., W.H. Aerenchyma formation and methane and oxygen exchange in rice. Soil Science Society of America Journal, Madison, v.57, n.2, p.386-391, 1993.

KLUDZE, H.K., DELAUNE, R.D. Straw application effects on methane and oxygen exchange and growth in rice. Soil Science Society of America Journal, Madison, v.59, n.3, p.824-830, 1995.

MILICH, L. The role of methane in global warming: Where might mitigation strategies be focused? Global Environmental Change-Human and Policy Dimensions, Oxford, v.9, n.3, p.179-201, 1999.

MITRA, S., JAIN, M.C., KUMAR, S., et al. Effect of rice cultivars on methane emission. Agriculture Ecosystems \& Environment, Amsterdam, v.73, n.2, p.177-183, 1999.

MOORE, T.R., DALVA, M. The influence of temperature and water table position on carbon dioxide and methane emissions from laboratory columns of peatland soils. Journal of Soil Science, Oxford, v.44, n.4, p.651-664, 1993.

NEUE, H.U. Methane emission from rice fields. Bioscience, Washington, v.43, n.7, p.466-474, 1993.

NUGROHO, S.G., LUMBANRAJA, J., SUPRAPTO, H., et al. Three-year measurement of methane emission from an Indonesian paddy field. Plant and Soil, Dordrecht, v.181, n.2, p.287-293, 1996

REDDY, K.R., PATRICK, W.H. Nitrogen transformations and loss in flooded soil and sediments. Critic Review Environment Contamination, [S. 1.], v.13, n.4, p.273-309, 1984.

RUSCHEL, A.P. O efeito estufa e a cultura arrozeira. Lavoura Arrozeira, Porto Alegre, v.45, n.401, p.3-4, 1992.

SASS, R.L. Factors in the production, emission and mitigation of methane from rice fields. Pelotas [s. n.], 1999. (Palestra apresentada no $1^{\circ}$ Congresso Brasileiro de Arroz Irrigado e $23^{\mathrm{a}}$ Reunião da Cultura do Arroz Irrigado. Não publicado).

SASS, R.L. Short summary chapter for methane. In: MINAMI, K., MOSIER, A., SASS, R. L. (eds). $\mathbf{C H}_{4}$ and $\mathbf{N O}_{2}$ : global emissions and controls from rice fields and other agricultural and industrial sources. Tsukuba : National Institute of AgroEnvironmental Science, 1994. p.1-7.

SASS, R.L., FISCHER, Y.B., TURNER, F.T., et al. Methane emission from rice fields: the effect of flood water management. Global Biogeochemical Cycles, Washington, v.6, n.2, p.249-262, 1992.

SINGH, S., SINGH, J.S., KASHYAP, A.K. Methane flux from irrigated rice fields in relation to crop growth and $\mathrm{N}$ fertilization. Soil Biology and Biochemistry, Oxford, v.31, n. 8, p.1219-1228, 1999 .

SUBADIYASA, N., ARYA, N., KIMURA, M. Methane emission from paddy fields in Bali Island, Indonesia. Soil Science \& Plant Nutrition, Tokyo, v.43, n.2, p.387-394, 1997.

WANG, Z.P., DELAUNE, R.D., MASSCHELEYN, P.H., et al. Soil redox and $\mathrm{pH}$ effects on methane production in a flooded rice. Soil Science Society of America Journal, Madison, v.57, n.2, p.382-385, 1993. 
WANG, B., NEUE, H.U., SAMONTE, H.P. Role of rice in mediating methane emission. Plant and Soil, Dordrecht, v.189, n.1, p.107-115, 1997.

WASSMANN, R., NEUE, H.U., ALBERTO, M.C.R., et al. Fluxes and pools of methane in wetland rice soil with organic inputs. Environmental Monitoring and Assessment, Dordrecht, v.42, n.1-2, p.163-173, 1996.

YAGI, K., MINAMI, K. Effect of organic matter application on methane emission from some Japanese paddy fields. Soil Science \& Plant Nutrition, Tokyo, v.36, n.4, p.599-610, 1990.

YAGI, K., TSURUTA, K.K., MINAMI, K. Automated monitoring of methane emission from a rice paddy field: the effect of water management. Global Biogeochemical Cycles, Washington, v.10, n.2, p.255-267, 1996.

YANG, S.S., CHANG, H.L. Effect of environmental conditions on methane production and emission from paddy soil. Agriculture Ecosystems \& Environment, Amsterdam, v.69, n.1, p.69-80, 1998.

YANG, S.S., CHANG, H.L. Effect of green manure amendment and flooding on methane emission from paddy fields. Chemosphere - Global Change Science, Oxford, v.3, n.1, p.41-49, 2001.

ZENGLER, K., RICHNOW, H.H., ROSSELLÓ-MORA, R., et al. Methane formation from long-chain alkanes by anaerobic microorganisms, Nature, London, v.401, n.6750, p.266-269, 1999.

Ciência Rural, v. 32, n. 6, 2002. 